\title{
Current Situation and Development Trend of Food Supplies in China
}

\author{
Sheng Yu \\ Major of Food Science and Technology, Department of Science and Technology, Beijing Normal University - \\ Hong Kong Baptist University United International College (UIC), Zhuhai, 519087, China
}

Keywords: Food self-sufficiency rate, Current situation of supplies, Development trend

\begin{abstract}
The present situation and change trend of food supply in China are studied in this paper. The study shows that the degree of self-sufficiency in food in China is still at a high level in general, but it has a downward trend in recent years. The difference between different products is also obvious. The decline of oil crops is obvious and the grain is basic self-sufficiency. The main causes of this change are the growth of China's economy, the short supply of food production and the small-scale operation model. The market and policy factors also have a certain impact.
\end{abstract}

In recent years, the grain production in China has shown an increasing trend year by year. But in contrast, the number of grain imports in China is also increasing. Not only food, such as meat, milk and other products are also in many imports. This phenomenon has aroused people's thinking. Is the food production in our country self-sufficient, and whether the national food security has a hidden danger?

At present, most of the research on food supply is focused on food, especially grain. There is not much research on other products and less overall research. In addition, many studies are based on domestic statistical data, focusing on production and import and export data, and less on the impact of inventory changes. With the rapid development of China's economy, people's living standards have been greatly improved, and more and more kinds of food are consumed. Therefore, based on the development and change of social economy, we must have a broader perspective to study the food supply problem, and study the whole food field. And, in a broad sense, food is included in all food. With the increase of grain output and the import of various kinds of products, the quantity of stock will inevitably be changed. If we do not make a comprehensive investigation, we cannot accurately predict the supply of food in China, and then affect the food security of our country.

\section{Current Situation of Food Supplies in China}

The study of food supply in China has found that the current domestic rate of self-sufficiency in food is still at a high level, reaching $86.43 \%$ in 2013.

Specifically, the self-sufficiency rate of spices, vegetables, fruits and so on is higher than that of $100 \%$, the above products are higher than the consumption volume, and a part of them are used for export. The self-sufficiency rate of oil crops is the lowest, only $45.50 \%$. The self-sufficiency rate of vegetable oil and sugar was also very low, which are $66.04 \%$ and $81 \%$ respectively. The rate of self-sufficiency in grain, meat and eggs are $98.97 \%, 97.15 \%$ and $99.92 \%$ respectively. Other foods, such as alcohol and animal fat, were also more than $85 \%$.

For some important food products, the rate of self-sufficiency in grain was over 95\%, of which rice and products are $101.37 \%$, and wheat and products were $96.04 \%$. However, there is also a low rate of self-sufficiency in some foods, for example, the self-sufficiency rate of palm oil and soybean are $3.17 \%$ and $15.41 \%$ respectively.

In general, the degree of self-sufficiency of food in China is high. A large amount of food, such as rations, can achieve basic self-sufficiency. The problem is mainly in the oil crops, like the need to import more products. Compared with most countries in the world, the level of self-sufficiency in the main food is higher in our country. Of course, China's grain self-sufficiency rate is lower than the 
United States, France and other countries, let alone Australia, Canada and other agricultural production countries.

It needs to be pointed out that many of the current researches are simplified methods to analyze the domestic grain self-sufficiency rate. The method of production plus net imports is used, but the change of inventory is not fully considered, and the statistical data obtained are quite error. For example, from 2000 to 2003, the domestic grain yield decreased year after year, the market showed the supply situation, need to use the inventory to meet the demand for food, but the application of the simplified method of self-sufficiency rate is still relatively high, to accurately reflect the food supply situation; by 2006, grain production growth in recent years, coupled with a some of the imported amount, grain stocks increased, a large part of the yield and no effective consumption, while the application of simplified method and overestimated the domestic consumption, the self-sufficiency rate is low. The following is a clear reflection of the rate of grain self-sufficiency calculated by two methods. The data show that the margin rate of self-sufficiency was 18.58 percent in 2003 and the margin rate of self-sufficiency was -2.81 percent in 2013.

Table 1. Grain self-sufficiency rate calculated by two methods

\begin{tabular}{lrrrrrrr}
\hline & 2001 & 2003 & 2005 & 2007 & 2009 & 2011 & 2013 \\
\hline Self-sufficiency rate 1 & 99.54 & 104.17 & 99.19 & 100.69 & 98.22 & 97.86 & 96.17 \\
Self-sufficiency rate 2 & 89.16 & 85.59 & 97.73 & 102.15 & 102.04 & 98.43 & 98.97 \\
Difference & 10.38 & 18.58 & 1.46 & -1.45 & -3.82 & -0.57 & -2.81 \\
\hline
\end{tabular}

\section{Development Trend of Food Supplies}

The research shows that the overall self-sufficiency of food in China is still at a high level, but it has gradually shown a declining trend in recent years. Moreover, there are great differences among different products, such as the rate of oil crop self-sufficiency is obviously decreased, and the grain is basically kept unchanged.

\subsection{Overall Trend}

The overall change in the food supply in China can be summarized into the following two stages. The first stage is the years before 2000. Although there are some fluctuations, food self-sufficiency rate but remained above $95 \%$. The lowest years have exceeded $93 \%$ in 1990 . The self-sufficiency rate is the highest, which is $101.01 \%$. The second stage is the years after 2000 . The food self-sufficiency rate showed a downward trend during the period, despite a slight rebound, but also failed to reach the level of $93 \%$, only $85 \%$ of the lowest.

In the past, China's overall food self-sufficiency rate and grain self-sufficiency rate of change curve basically is overlapping, from 1961 to 2003. The correlation coefficient between the two was 0.91; but in 2004, the difference is more and more obvious. From 2004 to 2013, the correlation coefficient is 0.38 between the two. The data showed that China's comprehensive food self-sufficiency rate showed a clear downward trend, while grain self-sufficiency rate has been maintained at a high level. Although it fluctuates, it can remain above 95\% in most cases.

\subsection{Difference between Products}

Changes in China's food self-sufficiency rate of different products showed great differences. Specifically, since 1990, oil crop product self-sufficiency rate decreased significantly, decreased from 1990 to 2013 52.92\%; second, the downward trend does not include soybeans, soy products are more obvious, from 1990 to 2013 with a decrease of $49.92 \%$; a period of time, the self-sufficiency rate decreased by $10 \% \sim 30 \%$ of the stimulant food, water and so on; self-sufficiency rate remained basically unchanged, fluctuations in the range of about $5 \%$ of grains, meat and so on; and at the same time, fish and sea food self-sufficiency rate is increased by $9.36 \%$. Moreover, in the past five years, that is, from 2008 to 2013, the self-sufficiency rate of beans and oilseeds has decreased by $24 \%$ and $17 \%$, while milk, sugar and sweeteners have also decreased significantly, which has decreased by 
$15 \%$ and $14 \%$ respectively.

In a variety of products, since 1990, the self-sufficiency rate is the largest decline in soybean, decreased by $78.82 \%$; secondly, for sesame seeds, peas and other products, reduced from $50 \%$ to $60 \%$; the same time, the self-sufficiency rate decreased by 30\% 50\% of the sorghum, cassava and honey; self-sufficiency rate is down $10 \% \sim 30 \%$ butter ghee, palm oil and so on; self-sufficiency rate decreased by $5 \% \sim 10 \%$ of the corn, rice, peanut and so on; self-sufficiency rate remained basically unchanged, fluctuations in the range of about $5 \%$ of the wheat, millet, sweet potato and so on; and at the same time, there are some products on the self-sufficiency rate of more than $5 \%$ liters such as tomatoes, grapes, etc..

In general, the self-sufficiency rate in various products is mainly decreasing: oil plants, some vegetable oils, feed ingredients, food processing materials, and all kinds of complementary foods. In recent years, the rate of self-sufficiency in milk and beef has also declined obviously. The decline in the self-sufficiency rate of the above products has caused a change in the overall rate of self-sufficiency in food in China. In the years of 1990 2013, the average annual rate of self-sufficiency in food in China has declined by $0.63 \%$. In recent years, the rate of decline has accelerated, and it has dropped by $1.27 \%$ annually.

\section{Change Causes Analysis of Food Supplies}

The main causes of this change are the growth of China's economy, the short supply of food production and the small-scale operation model. The market and policy factors also have a certain impact.

\subsection{Influence of the Economic and Social Development}

The study found that in countries lacking agricultural production resources, the economic development will inevitably lead to a decline in the rate of self-sufficiency in food. The economic growth of the city and the accelerated urbanization process must occupy many agricultural resources (such as land, water, etc.) to the development of food production. At the same time, with the improvement of people's living standard, the requirements of the diet will change greatly and the demand for food further expansion. It creates a huge contradiction between supply and demand, which makes the production of food in short supply, resulting in a decline in the rate of self-sufficiency in food. In recent years, with the rapid development of China's economy, the domestic agricultural production is also facing huge resource pressure. Although the annual output of China's staple agricultural products has kept increasing trend. The domestic demand can't meet the continuous growth of food demand under the condition of huge increase of consumption and upgrading of product structure.

\subsection{Influence of Small-Scale Operation Model}

For a long time, agricultural production has adopted a small-scale operation model in China. Such a business model has caused a lower production efficiency and higher operating costs, making the agricultural industry in our country very competitive in the world. In today's economic globalization, China's agricultural market has gradually realized opening to the outside world, and the import of agricultural products began to enter the domestic market. At the same time, the increasing cost of land, water and labor and the increasing attention to environmental protection will improve the total cost of China's agricultural products, further affect the competitiveness of China's agricultural products and speed up the decline of China's food self-sufficiency rate.

In 2004, China's agricultural products trade showed a deficit for the first time, and the trend of the deficit was more and more obvious. At present, the self-sufficiency rate of comprehensive food in China is only $86 \%$. In 2013, under such a complex situation, the Chinese government carried out the new definition of national food security, from the previous "protection" to "focus", and "moderate imports" as one of the food security strategy, put forward to more fully utilize other countries agricultural resources effectively supplement to domestic grain production. It can be said that soon, 
the economic and social development of our country will get further development. People's living standard will be further improved, and the food supply and demand will be further changed.

\subsection{Influence of Food Security Strategy}

Agricultural production has a certain particularity. In addition to providing employment, it ensures farmer income function of the outside. The food affects the national security and social stability to a large extent, the important role of all countries will not be ignored in agricultural production. Even countries with relatively backward agricultural production will not fully decide their own agricultural industries to the international market. Many countries have formulated a perfect food security strategy and adopted a protective policy for agricultural production.

Food security strategy cannot include all food products. In today's economic globalization, considering various considerations, the main products that will affect national security and domestic stability will only be protected. In most countries, food used as a basic ration is often given priority to protection. For example, Japan has given priority to rice protection to ensure that the rice self-sufficiency rate remains at a high level. From 1960 to 2006, Japan has been calculated based on the heat food self-sufficiency rate has dropped from the initial $79 \%$ to $39 \%$. The weight of grain self-sufficiency rate decreased from the initial $82 \%$ to $27 \%$. However, the rice self-sufficiency rate has long been maintained at a high level, which is higher than 95\%.

From 1990 to 2013, China's comprehensive food self-sufficiency rate has decreased from 101.01\% to $86.43 \%$, but the self-sufficiency rate of grain has decreased by $4.29 \%$, and the current value is still over $98 \%$. The self-sufficiency rate of soybeans decreased by $78.82 \%$, but only about $15 \%$ at present. However, the self-sufficiency rate of rice decreased by only $5.33 \%$, and the current rate is still about $100 \%$. The self-sufficiency rate of wheat has not only decreased but also increased by $2.08 \%$, and the current self-sufficiency rate has also been over 96\%. This change is largely due to the special agricultural policy implemented by the government of our country. Although China has a vast land area, but a large population, the per capita arable land is only reached the world average of forty percent, the per capita water resources are less than the world average of one fourth, so it is impossible to completely protect all the supplies of agricultural products. To make full use of agricultural resources in other countries to provide a supplement is very necessary. Specific to the product categories, mainly rice and wheat rations are due to its support, the restriction of import quota protection policy; and soybean is already open to the international market, lower tariffs, and no quota restrictions on imports of soybeans have flocked to the domestic market.

\subsection{Influence of Other Factors}

Since 2008, grain production in China has increased year by year, but the rate of grain self-sufficiency has not increased significantly. This is mainly due to the growing domestic grain prices, and the grain prices in the international market have more and more comparative advantages. This makes the import of grain more and more, and the domestic grain is directly stored in the warehouse. Moreover, with the improvement of people's living conditions, they are no longer satisfied with simply filling their stomachs, and the demand for food is higher and higher. This also causes many imports of other kinds of foods. This shows that there are many factors affecting the rate of self-sufficiency in food in our country. In some cases, the growth of net imports is not due to the lack of domestic production, but because the import tariffs of some products are very low, and the cost advantage will affect the quantity of imports and exports. In addition, the domestic policy of agricultural support, especially the price policy, exchange rate changes and international market fluctuations, will also have a great impact. Of course, the safety of food also affects people's choice of products, which leads to changes in the import and export of related products.

\section{Summary}

In general, the overall self-sufficiency of food in China is still at a higher level. Compared with the world average, the degree of food self-sufficiency is still higher. From a large trend, the rate of 
self-sufficiency in food has shown a significant decline in recent years. However, there are differences among different products. The decline of oil crops is obvious, grain basically maintain self-sufficiency. There are many reasons for the change of food supply in China. Among them, economic development promotes the improvement of living standard of residents, small scale business mode lacks market competitiveness, and food safety strategy leads to the change of food supply structure and so on. It is worth noting that to ensure a high level of food self-sufficiency, grain production should be maintained. If food production is reduced, the rate of food self-sufficiency will be adversely affected. In addition, the changes in the global market, the agricultural support policy, the food safety and so on, will affect the supply of food in our country to a certain extent. Our country should take the necessary measures to ensure the self-sufficiency of the main food products, to guarantee the national food security.

\section{References}

[1] Cao Zhihong. Changes in Chinese Food Consumption and Agricultural Production Requirements Based on Cereal Equivalent [J]. 2013, 35(11): 2181-2187.

[2] Su Chang, Zhang Bing, Wang Huijun, et al. The status and trend of cereal consumption among Chinese adults in nine provinces (municipality) from 1989 to 2006 [J]. Chinese Journal of Preventive Medicine, 2011, 45(9): 798-801.

[3] Wang Xiaohu, Cheng Guangyan, Zhou Lin, et al. Development Trend and Scientific-technological Innovation Needs of Food and Nutrition in China [J]. Journal of Agricultural Science and Technology, 2015, 17(4): 1-7.

[4] Jiang Xun. Study on the Status of China's Food Supply and Demand Based on GIS [J]. Journal of North China Institute of Aerospace Engineering, 2017, 27(4): 28-30. 